\title{
Impact of Ultrashort Laser Nanostructuring on Friction Properties of AISI 314 LVC
}

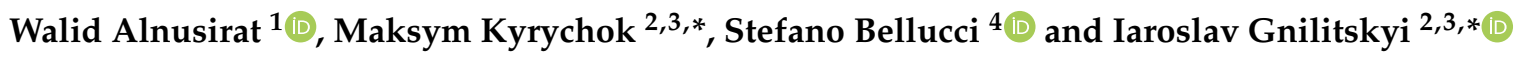 \\ 1 Maan University College, Al-Balqa Applied University, Salt 19117, Jordan; walidnusir@bau.edu.jo \\ 2 NoviNano Inc., 79021 Lviv, Ukraine \\ 3 Department of Photonics, Lviv Polytechnic National University, 79000 Lviv, Ukraine \\ 4 INFN-Laboratori Nazionali di Frascati, 00044 Frascati, Italy; stefano.bellucci@lnf.infn.it \\ * Correspondence: Maksym.Kyrychok.MMN.2020@lpnu.ua (M.K.); iaroslav.gnilitskyi@novinano.com (I.G.)
}

check for

updates

Citation: Alnusirat, W.; Kyrychok, M.; Bellucci, S.; Gnilitskyi, I. Impact of Ultrashort Laser Nanostructuring on Friction Properties of AISI 314 LVC. Symmetry 2021, 13, 1049. https://doi.org/10.3390/ sym13061049

Academic Editors: Sergei D. Odintsov, Christophe Humbert and Andrea Lavagno

Received: 3 April 2021

Accepted: 4 June 2021

Published: 10 June 2021

Publisher's Note: MDPI stays neutral with regard to jurisdictional claims in published maps and institutional affiliations.

Copyright: (c) 2021 by the authors. Licensee MDPI, Basel, Switzerland. This article is an open access article distributed under the terms and conditions of the Creative Commons Attribution (CC BY) license (https:/ / creativecommons.org/licenses/by/ $4.0 /)$.

\begin{abstract}
Laser irradiation yields a powerful tool to modify the symmetry and asymmetry features of materials surfaces. In this paper, femtosecond laser-induced periodic surface structures were applied on stainless steel AISI 314, specially hardened by a low-vacuum carburizing procedure. Symmetry modifications in the surface's morphology and chemistry before and after the laser treatment were investigated by SEM and EDS, respectively. Coefficient of friction (COF) was observed in dry sliding condition by using block-on-ring sliding test. The results show that COF values are substantially lower after laser-induced periodic surface structures (LIPSS) surface treatment.
\end{abstract}

Keywords: femtosecond laser; LIPSS; COF; laser modification; dry sliding test

\section{Introduction}

Friction is responsible for more than $25 \%$ of energy consumption in all human areas round the world [1]. In nature, especially snakes have a selected morphology of skin, i.e., they show a synergy between nanoscale and submicron features, allowing for a significant reduction in the friction in dry conditions [2]. Another example is the skin of a shark, which consists of small scales with parallel riblets [3].

There are many methods that suggest breeding such a specific morphology and the corresponding symmetry properties. However, conventional optical lithography techniques require complex masks, while e-beam lithography and ion-beam lithography require expensive equipment. Single-step muscless optical patterning techniques also exist, notably simple direct laser writing (DLW) [4] and the more complex multi-beam interference [5] and the even more advanced direct laser interference patterning (DLIP) [6]. All these aforementioned laser surface treatments are able to form microscale patterns on the surface and all substantially decrease the coefficient of friction (COF). It has been proven that laser surface microstructures play the role of lubricant reservoirs. Moreover, there is a laser method, a phenomenon named Laser Induced Periodic Surface Structures (LIPSS) [7] which provides a nanoscale pattern due to self-organized processes and beyond the diffraction limit.

LIPSS are observed on most materials, from metals to graphene [8-11] and their importance has been demonstrated for various scientific, biomedical, and industrial applications [12,13]. The formation mechanism commonly attributed to regular periodic structures is said to be due to the interference of incident laser light with a wave propagating at the surface, resulting in a periodic intensity modulation that is imprinted into the fabric. The efficacy theory is predicated on analytical solutions of Maxwells equations within the presence of a randomly distributed rough surface and yields an expression for the inhomogeneous energy deposition into the fabric [14]. The most important assumptions behind this idea are that the surface roughness is randomly distributed, its thickness must be much smaller than both the illuminating wavelength and therefore the period of laser induced surface structures (LIPSS) being studied [15]. 
Laser nanostructuring, i.e., LIPSS, appears to be an appealing method, as it is stated in $[16,17]$. Upon initiation of the experiment, LIPSS were generated over a large area on 100Cr6 steel and titanium alloy (Ti6Al4V). Paraffin oil and commercial engine oil were used for reciprocal sliding, which caused elucidation of the tribological properties of the experimental samples. That resulted in a very low friction coefficient $(0.15)$ shown on the samples with the use of both lubricants. Upon initiation of the experiment on Ti alloy surfaces, the nanostructured surfaces showed high and non-stable friction coefficient values (from 0.2 to 0.6 ) with the use of paraffin oil, and reduced values (0.12-0.14) with engine oil; this is determined by an advantageous combination of LIPSS and additives of engine oil, which can profoundly cover the nanostructured surfaces. To prove the tribological properties of the treated surfaces, authors in [18] have treated X5CrNi1810 stainless steel discs with LIPSS. Tribological tests have proved a decrease in friction and wear compared to an untreated reference sample.

The laser-induced nanostructures, which are produced on the surface with the application of the laser treatment, play a fundamental role and serve as lubricant reservoir during the contact and as debris pockets to minimize the abrasion due to particles spread on the interface. However, in all mentioned studies LIPSS structures are disappearing after 10-20 m of sliding test even with oil.

In the paper, we used samples of stainless steel AISI 314 L specially hardened by low vacuum carburized procedure and modified with LIPSS to reduce coefficient of friction (COF). We demonstrated that LIPSS of high quality can be obtained also on hardened steel. The COF was observed in dry sliding test by using as counter body material (usually AISI 314 L). The LIPSS on stainless steel, in one-fold hardened, were feasible after $10 \mathrm{~m}$ of sliding dry test.

\section{Materials and Methods}

\subsection{Preparation of Samples}

The material which was used is AISI 316L austenitic stainless steel. Moreover, AISI 316L was treated with the special procedure of low temperature carburized (LTC) in order to improve hardness characteristics of the samples. The samples were prepared as extruded bars and then a set of micro hardness measurements were performed in the diagonal of the cross-section between the LTC zone and the untreated zone on a depth of $100 \mu \mathrm{m}$. The hardness of the LTC layer was measured around $1200 \mathrm{HV}_{0.25}$ as shown in Figure 1.

\subsection{Laser-Treated Processing}

Ablative LIPSS are produced on the surface of AISI 316L LVC by femtosecond laser system PHAROS from Light Conversion (Vilnius, Lithuania) at laser wavelength $1030 \mathrm{~nm}$ (mid-infrared). Such a laser system provides a compression of pulse up to $266 \mathrm{fs}$. The polarization of the laser beam was tuned by half-wave plate. The laser beam was let down to galvanoscanner head "ExcelliScan" (ScanLab, Munich, Germany) in order to accelerate the laser process. The focus distance of F-theta lens, that was embedded into the galvo head, was equal to $56 \mathrm{~mm}$. The scanning speed was vs. $=100 \mathrm{~mm} / \mathrm{s}$ a triangle wave strategy (right-left-right). Part of the laser system-galvoscanner head with F-theta lens in the processing of the stainless-steel bar-is shown in Figure 2. 


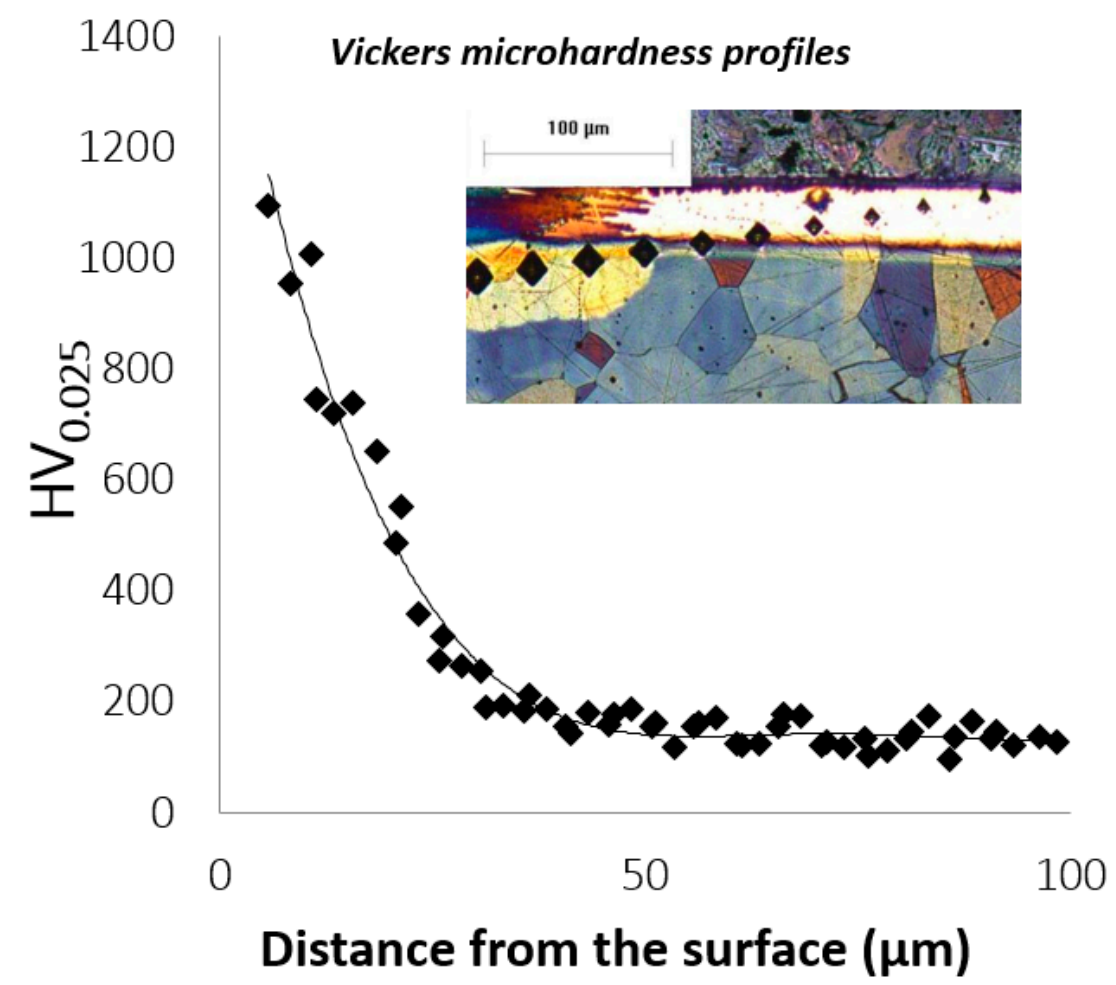

Figure 1. Graph of Vickers microhardness profile measured from AISI 314 LVC. The inset shows the cross section of the bars after low temperature carburized procedures.

\begin{tabular}{lccccc}
\hline Material & Pulse Duration & Energy per Pulse & Repetition Rate, kHz & $\begin{array}{c}\text { Direction of Polarization Respect } \\
\text { Scanning Direction }\end{array}$ & Overlap, $\mu$ m \\
\hline 316L LTC & $266 \mathrm{fs}$ & $150 \mathrm{~nJ}$ & $200 \mathrm{kHz}$ & $45^{\circ}$ & 4 \\
\hline
\end{tabular}

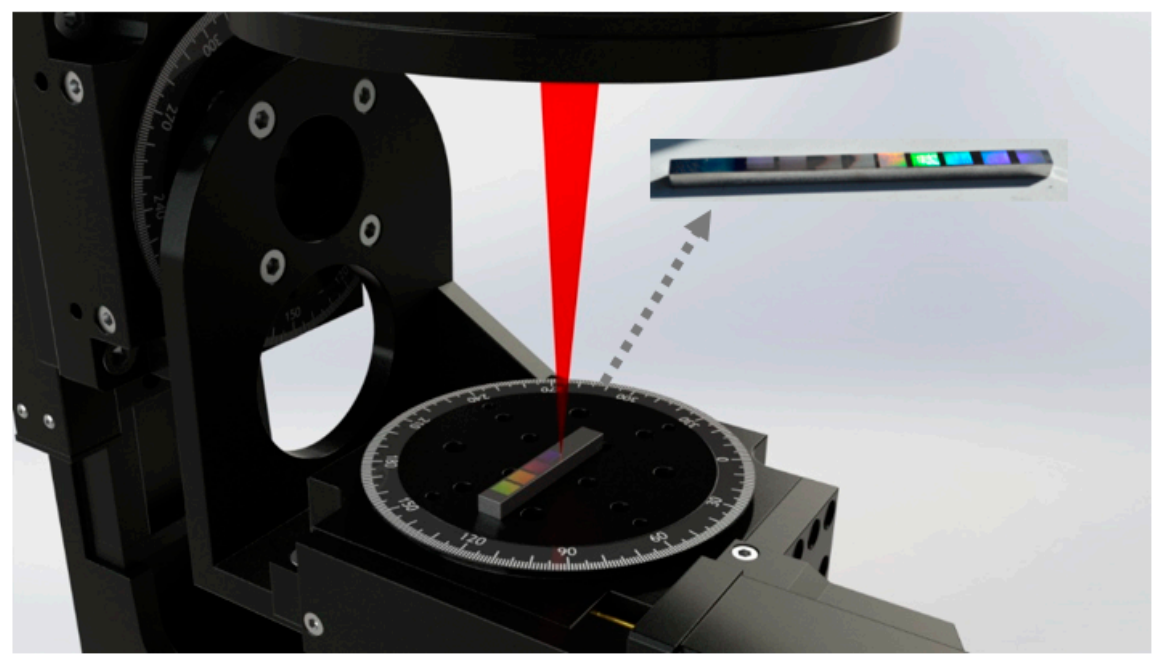

Figure 2. Laser Setup.

\subsection{Tribological Test}

The LIPSS-treated AISI316L surfaces' tribological conduct was studied in sliding state via dry sliding tests within a block-on-ring arrangement (Figure 3). The nanopatterned surface was fixed at $45^{\circ}$ with regard to the cylinder's sliding movement. The slider-oncylinder tribometer (block-on-ring contact geometry, ASTMG77 [19]) was used for dry 
sliding test. We machined the sliders from AISI 316L LVC and used different areas on them as counterface material (i.e., rotating cylinders with $40 \mathrm{~mm}$ diameter). Thus, we used untreated AISI 316L austenitic stainless steel, with hardness of 285HV0:05 and surface roughness Ra of $0.10 \mu \mathrm{m}$. The initial austenitic stainless steel allowed us to measure the behavior of self-mating tribological couples.

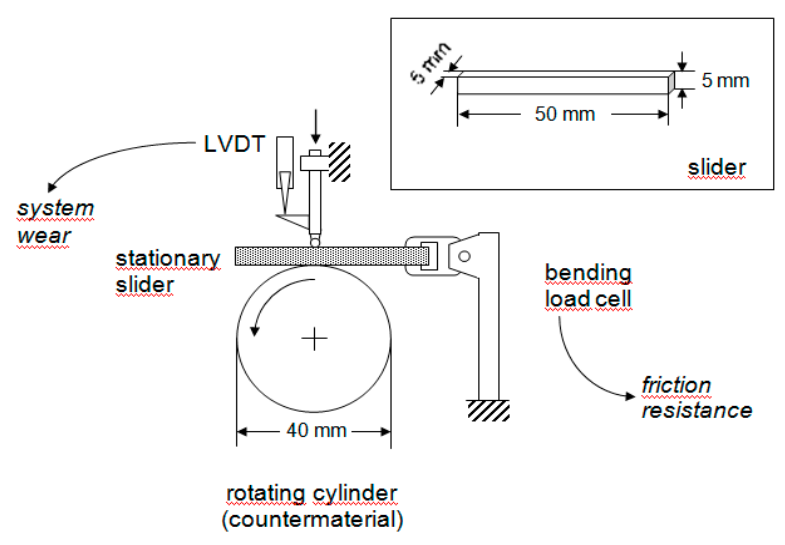

(a)

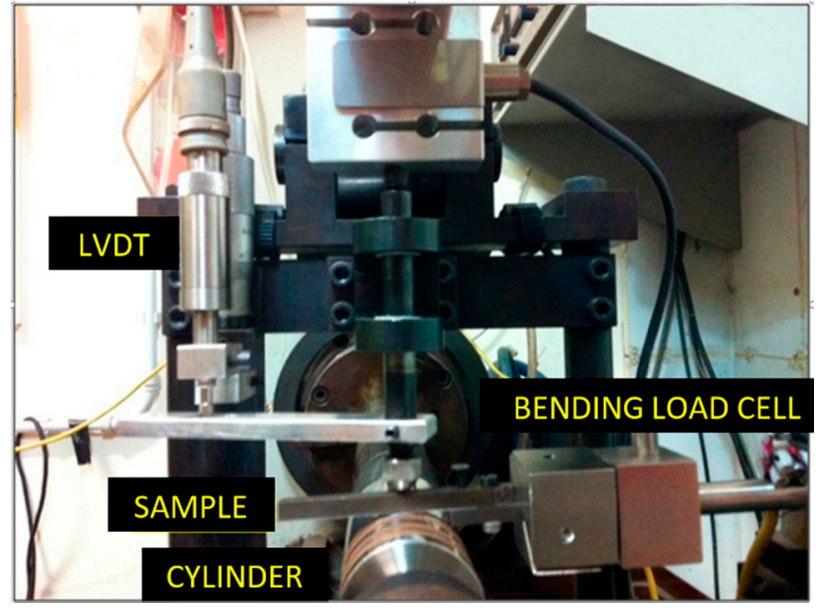

(b)

Figure 3. Tribological test: sketch of experiment (a) and real tribology test setup (b). LVDT-load, Slider-sample, Cylinder-counterbody.

\subsection{Morphological Characterization (SEM and AFM)}

Field Emission FEI Nova NanoSEM 450 (Billerica, MA, USA) was employed to measure surface morphology and to assess the corresponding symmetry modifications due to the laser treatment of the surface. In order to obtain high-quality images secondary electrons imaging mode was used. The NanoSEM 450 is equipped with X-EDS Bruker QUANTAX-200 that allows the detection of the atomic percentage of each element. The surface roughness was measured by using an atomic force microscope (AFM) operating in non-contact optical mode.

\section{Results and Discussion}

\subsection{Morphological Analysis}

The LIPSS-induced structures' morphology and the correspondingly induced symmetry modifications, before and after applying the laser treatment upon the surface, were studied upon the SEM. From Figure 4 we can see that periodic nanostructures were formed due to irradiation by the linear-polarized femtosecond laser pulses. It is clearly seen that the nanostructures are homogeneously distributed and in a uniform and parallel shape. Additionally, the nanostructures are present over the entire treated zone with an average periodicity of $810 \mathrm{~nm}$. Figure 4a shows that nanostructures are generated in state, in which ripples are orientated at $45^{\circ}$ relative to the scanning direction. Figure $4 \mathrm{~b}$ shows nanostructures between untreated and treated areas. Moreover, the image is tilted by $40^{\circ}$ in order to see the height of the ripples. On the tilted image smaller nanostructures are clearly visible between ripples. These smaller nanostructures are commonly attributed to high-spatial frequency LIPSS (HSFL) with a period equal to 1/10 of the laser wavelength [14].

The morphology of the laser-treated surface on stainless steel observed by AFM displays the surface homogeneously covered by periodically regular submicrostructures (Figure 5). The average roughness was estimated to be equal to $290 \pm 30 \mathrm{~nm}$ that is substantially higher with respect to the untreated one. This is a remarkable change from the surface's symmetry standpoint, totally due to the effect produced on the surface by the laser irradiation. 

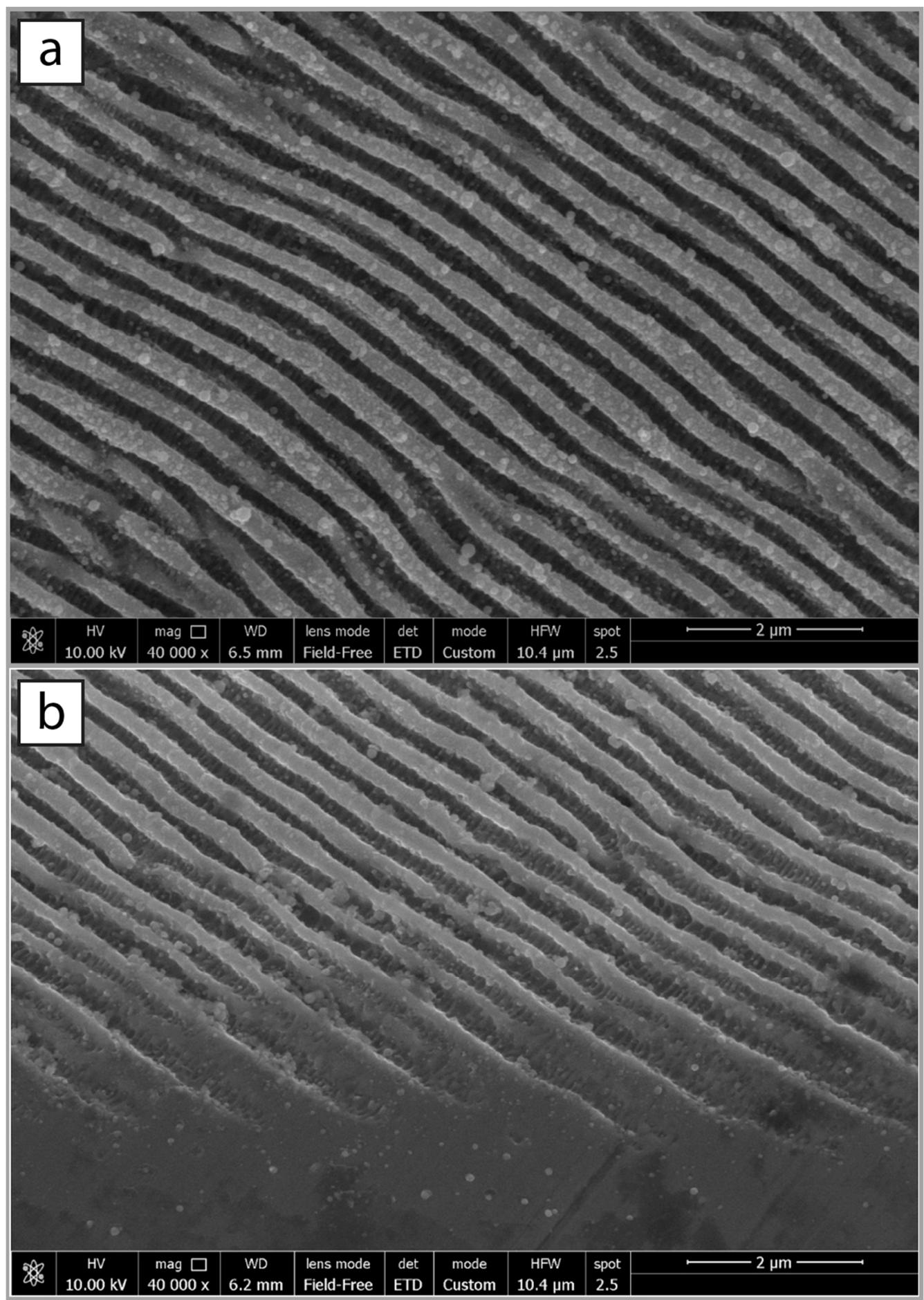

Figure 4. SEM image of LIPSS-treated surface of AISI 314L LVC (a). Tilted image of LIPSS with angle $40^{\circ}$ at the untreated zone (b).

Figure 6 presents a EDS spectrum images of both the LIPSS- treated stainless steel surface and the untreated area. All elements remain almost the same except for the appearance of the oxygen peak in the laser-treated spectrum. This suggests the formation of a laser-induced surface oxidative film. 


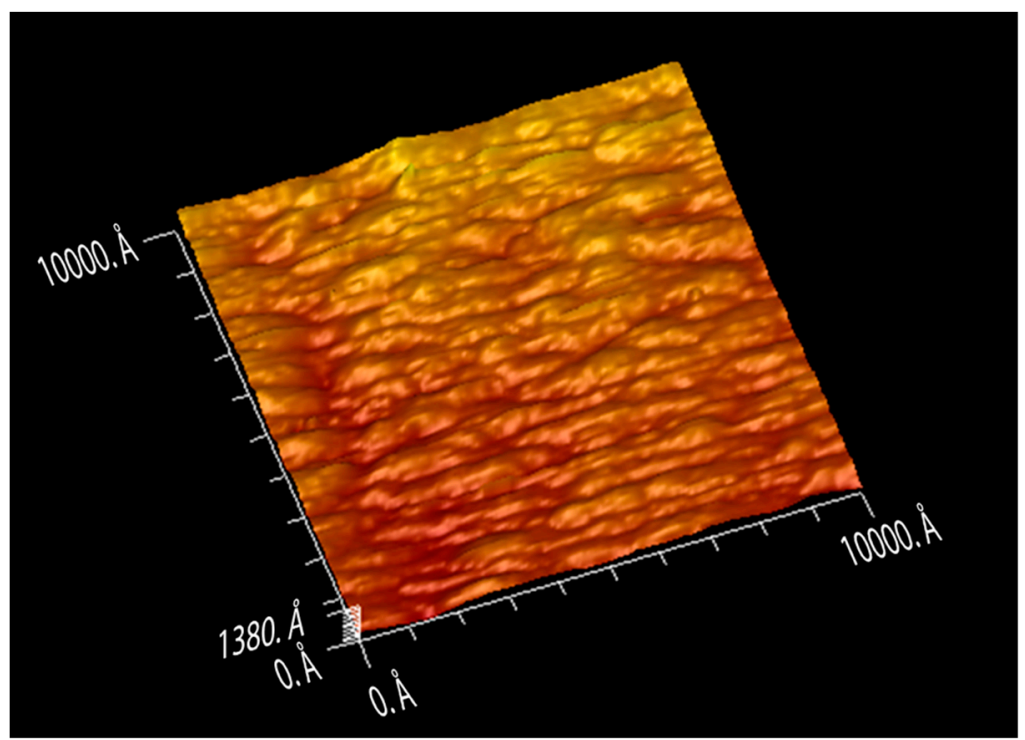

Figure 5. AFM image of LIPSS-treated surface of AISI 314L LVC.

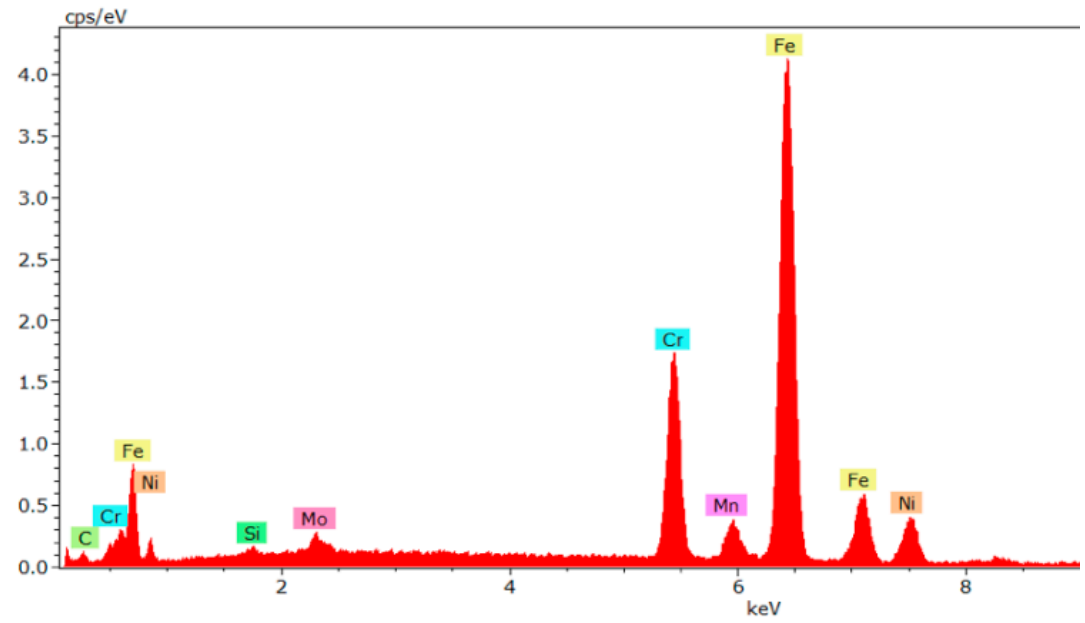

(a)

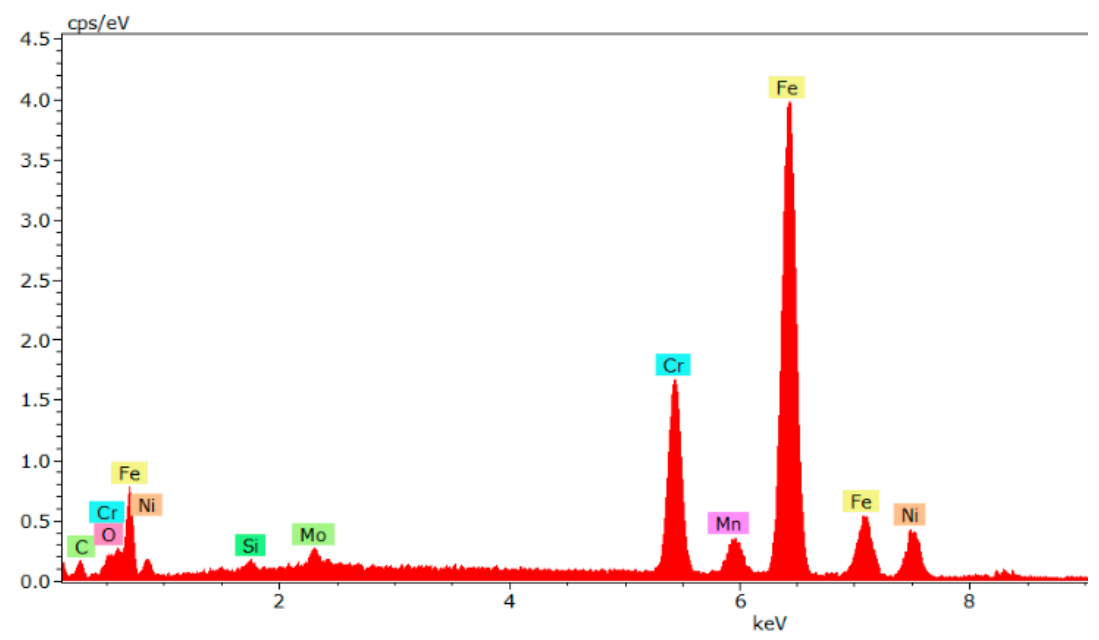

(b)

Figure 6. Energy-dispersive X-ray spectroscopy (EDS) of untreated (a) and LIPSS-treated surface (b) of AISI 314L LVC. 


\subsection{Tribological Test in Dry Conditions}

The average COF values are shown in Figure 7, which are measured in the friction vs. the distance plots. As can be seen from Figure 7, the average COF values of LIPSSmodified surfaces are smaller than those on the untreated surface irrespective of the countermaterial. These results are well in line with [15] in terms of the description of the influence of micro/nanogrooved surfaces on friction. The effect of shorter stiction length causes the friction coefficient to decrease, as well as the ratio between the width and height of the nanogrooves.

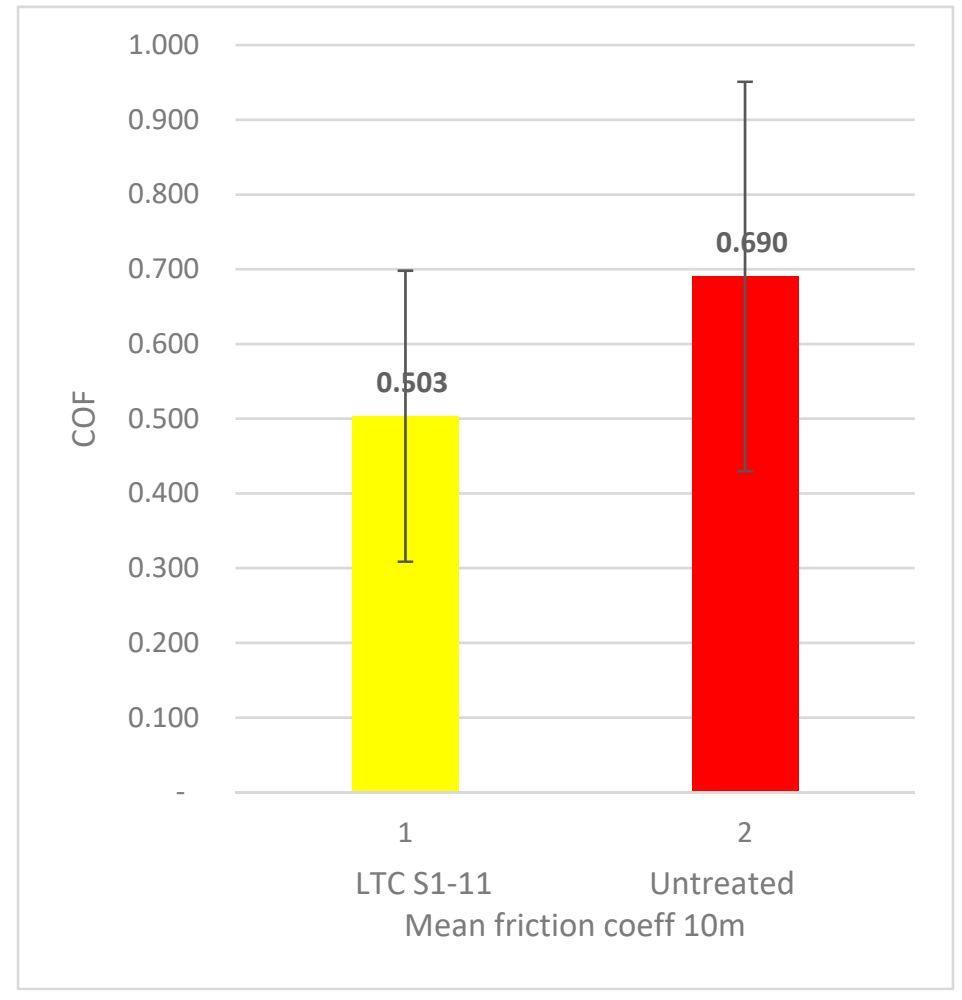

Figure 7. Dry sliding test: Coefficient of friction (averaged over the first $10 \mathrm{~m}$ of sliding) of AISI 316L LVC, untreated or modified.

The wear scars' morphology was examined with the use of the SEM as per the dry sliding tests, as shown in Figure 8. When sliding in the self-mating configuration (AISI 316L LVC vs. AISI 316L), the untreated surface (Figure 8a,d) definitely shows plastic deformation and there is no evidence of the typical protective oxide layer, which is created upon low loads such as $5 \mathrm{~N}$ [20]. In contrast, the LIPSS-treated surfaces after the conducted experiments are partly covered with fine oxidized wear debris and with powdery material visible at low magnification.

The impact of the use of LIPSS technology on friction can be determined by the fact that nanostructures are reducing the contact area between the asperities of the mating surfaces. As a consequence, adhesion is reduced and the oxidized wear debris is entrapped. The flow of statistical deviation is quite critical, although similar behavior has also been observed [16,21]. 

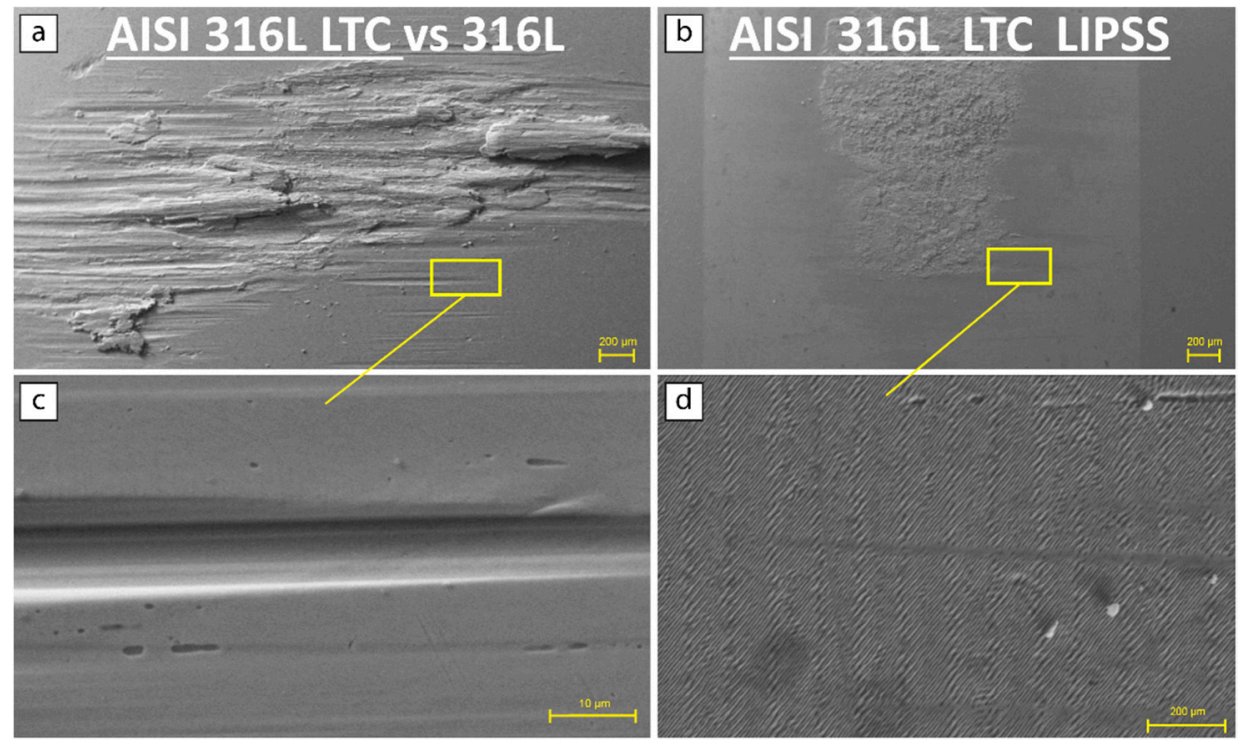

Figure 8. Dry sliding test: morphology of worn surfaces on untreated surface $(\mathbf{a}, \mathbf{c})$ and modified by LIPSS (b,d).

\section{Conclusions}

We examined the sliding behavior of AISI $316 \mathrm{~L}$ austenitic stainless steel before and after laser surface treatment with LIPSS technology. As a result, the sub-wavelength nano-ripples with an efficient uniformity over the large areas were created with diagonal orientations to the sliding direction. We have also studied their influence on the tribological properties of the surfaces. Dry (block-on-ring) sliding tests were conducted with the use of AISI $316 \mathrm{~L}$ counter body materials. In principle, the laser treatment with LIPSS technology in dry conditions has a great effect on the coefficient of friction and it reduces the coefficient of friction down to $40 \%$ compared to the untreated one, although the flow of statistical deviation is quite critical. The impact of LIPSS technology on friction appears since nanostructures are reducing the contact area between the asperities of the mating surfaces. As a consequence, adhesion is reduced and the oxidized wear debris is entrapped.

Author Contributions: Conceptualization, W.A. and I.G.; methodology, I.G. and M.K.; resources, S.B.; writing-original draft preparation, W.A., S.B. and I.G.; writing—review and editing, W.A., M.K., S.B. and I.G. All authors have read and agreed to the published version of the manuscript.

Funding: The paper was supported by the National Research Fund of Ukraine project 2020.02/0390.

Acknowledgments: We acknowledge to Massimo Tonelli and Mauro Zaparolli (CIGS-University of Modena and Reggio Emilia) for the SEM characterizations.

Conflicts of Interest: The authors declare no conflict of interest.

\section{References}

1. Holmberg, K.; Erdemir, A. Influence of tribology on global energy consumption, costs and emissions. Friction 2017, 5, 263-284. [CrossRef]

2. Abdel-Aal, H.A.; El Mansori, M. Tribological analysis of the ventral scale structure in a python regius inrelation to laser textured surfaces. Surf. Topogr. Metrol. Prop. 2013, 1, 015001. [CrossRef]

3. Reif, W.E.; Dinkelacker, A. Hydrodynamics of the squamation in fast swimming sharks. Neues Jahrbuch Geol. Palaeontol. Abhandlungen 1982, 164, 184-187. [CrossRef]

4. Ancona, A.; Joshi, G.S.; Volpe, A.; Scaraggi, M.; Lugarà, P.M.; Carbone, G. Non-Uniform Laser Surface Texturing of an Un-Tapered Square Pad for Tribological Applications. Lubricants 2017, 5, 41. [CrossRef]

5. Burrow, G.M.; Gaylord, T.K. Multi-Beam Interference Advances and Applications: Nano-Electronics, Photonic Crystals, Metamaterials, Subwavelength Structures, Optical Trapping, and Biomedical Structures. Micromachines 2011, 2, 221-257. [CrossRef] 
6. Milles, S.; Soldera, M.; Voisiat, B.; Lasagni, A.F. Fabrication of superhydrophobic and ice-repellent surfaces on pure aluminium using single and multiscaled periodic textures. Sci. Rep. 2019, 9, 1-13. [CrossRef] [PubMed]

7. Bonse, J.; Kruger, J.; Höhm, S.; Rosenfeld, A. Femtosecond laser-induced periodic surface structures. J. Laser Appl. 2012, $24,042006$. [CrossRef]

8. Buividas, R.; Mikutis, M.; Juodkazis, S. Surface and bulk structuring of materials by ripples with long and short laser pulses: Recent advances. Prog. Quantum Electron. 2014, 38, 119-156. [CrossRef]

9. Gnilitskyi, I.; Orazi, L. Mechanisms of high-regularity periodic structuring of silicon surface by sub-mhz repetition rate ultrashort laser pulses. Appl. Phys. Lett. 2016, 109, 143101. [CrossRef]

10. Miyaji, G.; Miyazaki, K. Origin of periodicity in nanostructuring on thin film surfaces ablated with femtosecond laser pulses. Opt Express 2008, 16, 16265-16271. [CrossRef] [PubMed]

11. Zou, T.; Zhao, B.; Xin, W.; Wang, Y.; Wang, B.; Zheng, X.; Xie, H.; Zhang, Z.; Yang, J.; Guo, C.-L. High-speed femtosecond laser plasmonic lithography and reduction of graphene oxide for anisotropic photoresponse. Light. Sci. Appl. 2020, 9, 1-11. [CrossRef] [PubMed]

12. Gnilitskyi, I.; Mamykin, S.; Lanara, C.; Hevko, I.; Dusheyko, M.; Bellucci, S.; Stratakis, E. Laser Nanostructuring for Diffraction Grating Based Surface Plasmon-Resonance Sensors. Nanomaterials 2021, 11, 591. [CrossRef] [PubMed]

13. Kuznietsov, O.; Tsibidis, G.; Demchishin, A.; Demchishin, A.; Babizhetskyy, V.; Saldan, I.; Bellucci, S.; Gnilitskyi, I. Femtosecond Laser-Induced Periodic Surface Structures on 2D Ti-Fe Multilayer Condensates. Nanomaterials 2021, 11, 316. [CrossRef] [PubMed]

14. Sipe, J.E.; Young, J.F.; Preston, J.S.; van Driel, H.M. Laser-induced periodic surface structure. I. Theory. Phys. Rev. B 1983, $27,1141$. [CrossRef]

15. Skolski, J.Z.P.; Rmer, G.R.B.E.; Obona, J.V.; Ocelik, V.; Veld, A.J.H.; de Hosson, J.T.M. Laser-induced periodic surface structures: Fingerprints of light localization. Phys. Rev. B 2012, 85, 075320. [CrossRef]

16. Bonse, J.; Koter, R.; Hartelt, M.; Spaltmann, D.; Pentzien, S.; Höhm, S.; Rosenfeld, A.; Krüger, J. Tribological performance of femtosecond laser-induced periodic surface structures on titanium and a high toughness bearing steel. Appl. Surf. Sci. 2015, 336, 21-27. [CrossRef]

17. Yasumaru, N.; Miyazaki, K.; Kiuchi, J.; Sentoku, E. Frictional properties of diamond-like carbon, glassy carbon and nitrides with femtosecond-laser-induced nanostructure. Diam. Relat. Mater. 2011, 20, 542-545. [CrossRef]

18. Gnilitskyi, I.; Rota, A.; Gualtieri, E.; Valeri, S.; Orazi, L. Tribological properties of high-speed uniform femtosecond laser patterningon stainless steel. Lubricants 2019, 7, 83. [CrossRef]

19. ASTMG77-05. Standard Test Method for Ranking Resistance of Materials to Sliding Wear Using Block-on-Ring Wear Test. 2010. Available online: https:/ / www.nen.nl/en/astm-g77-05-2010-en-1073455 (accessed on 1 April 2021).

20. Yu, C.; Yu, H.; Liu, G.; Chen, W.; He, B.; Wang, Q.J. Understanding Topographic Dependence of Friction with Micro- and Nano-Grooved Surfaces. Tribol. Lett. 2014, 53, 145-156. [CrossRef]

21. Gnilitskyi, I.; Rotundo, F.; Martini, C.; Pavlov, I.; Ilday, S.; Vovk, E.; Ilday, F.Ö.; Orazi, L. Nano patterning of AISI 316L stainless steel with Nonlinear Laser Lithography: Sliding under dry and oil-lubricated conditions. Tribol. Int. 2016, 99, 67-76. [CrossRef] 